\title{
La convivencia religiosa en una localidad indígena: el caso de Mecayapan, México
}

\author{
Religious connivance in an indigenous village: \\ the case of Mecayapan, Mexico
}

Felipe R. Vázquez Palacios* RESUMO
El estudio ofrece a los especialistas en reli-
gión la oportunidad de comprender la frag-
mentación del campo religioso local y su signi-
ficado en términos de la dinámica social, a
partir de un enfoque antropológico centrado
en el municipio de Mecayapan, México.
PALAVRAS-CHAVE: convivencia religiosa; grupos
indígenas; México; Mecayapan.
ABSTRACT

This study offer to specialists in religion the opportunity to understand the fragmentation of local religious field and its significance in terms of social dynamics, from an anthropological approach focused on Mecayapan Municipality, Mexico.

KEYWORDS: religious connivance; indigenous groups; Mexico, Mecayapan.

El objetivo de este trabajo es analizar la fragmentación del campo religioso local y su significado en términos de la dinámica social, a partir de un enfoque antropológico que permita entender cómo, porqué y para qué, se genera esta convivencia religiosa. El municipio de Mecayapan es representativo de los casos cada vez más comunes donde el catolicismo es minoritario y se encuentra cohabitando en competencia con otras agrupaciones religiosas.

Son pocos los análisis en ciencias sociales que se han ocupado del análisis del cómo conviven en competencia diversos grupos religiosos en espacios relativamente pequeños, y porqué se siguen fragmentado y propiciando la diversidad religiosa: Jackson (1984), Juárez (1989), Vallado (1989), Froehle (1994). Los trabajos presentan cómo se establecen las

\footnotetext{
Doutor em Antropologia Social pela Universidad Iberoamericana e Pesquisador do Centro de Investigación y Estudios Superiores em Antropología Social (CIESAS) / México.
} 
diversas agrupaciones religiosas en las localidades de estudio y los embates que sufren para su establecimiento y consolidación y la competencia que se genera entre ellos; dejándonos reflexiones interesantes en torno al conflicto religioso que se genera y el impacto social que ello representa para el área de estudio, que por lo general es negativo. Se hace hincapié en los factores de crisis económica y política que generan la diversidad de agrupaciones, pero pocas reflexiones sobre patrones de coexistencia entre agrupaciones religiosas. Esto, quizás, debido a la tendencia de una época (hace más de una década) donde era importante resaltar el conflicto, y los que escapaban a la seducción del conflicto se quedaban en las generalidades de la diversidad y la forma en que se adaptan y adoptan las agrupaciones religiosas con formas preexistentes propias de la localidad, fortaleciendo o renovando en muchos de los casos estructuras que se encontraban en vías de extinción. Por ello, es que en este trabajo me avoco a responder cuestiones como: ¿Qué papel juegan las diversas agrupaciones religiosas en la localidad? ¿Cómo se da la coexistencia de estas religiosidades en estos espacios tan pequeños? ¿Cuál es la tendencia y futuro de este tipo de formaciones sociales?

\section{Contexto del área de estudio}

Mecayapan se ubica al sureste del estado de Veracruz, localizado aproximadamente a 45 kilómetros del golfo de México. En la actualidad, la población total del municipio es en un $90 \%$ bilingüe, hablante de nahua y español (INEGI, 2001), posee asimismo amplias problemáticas de marginación, escasez de tierras, emigración masiva, despoblamiento, entre otros; sin embargo, ha respondido a la problemática regional de manera particular como localidad marcada por su gran número de agrupaciones religiosas predominantemente de corte evangélico. En 1996, el poblado de Tatahuicapan, se separa de Mecayapan, dejando al poblado de la Perla sin continuidad territorial con el resto de su municipio de pertenencia. 


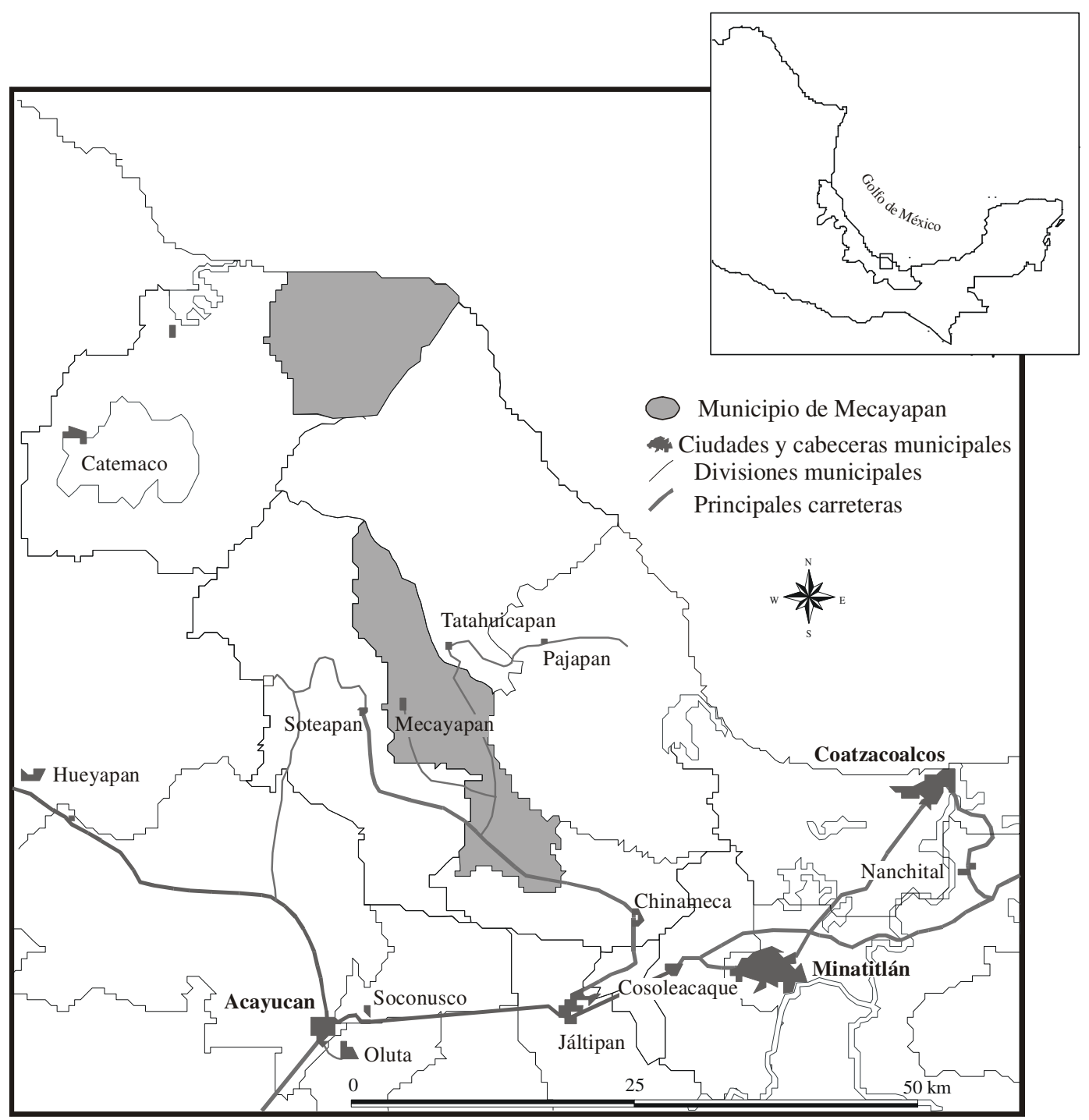

Fuente: Rafael Palma y Eric Leonard, Fondo Cartográfico: Banco Sotavento IRD-CIESAS.

Según la historia oral, los antepasados de Mecayapan salieron de Huimanguillo, en el estado de Tabasco y luego de pedir permiso a los popolucas, que ya estaban establecidos ahí, se quedaron en este lugar. ${ }^{1}$ Desde finales del siglo XIX y principios del XX, la falta de caminos, la lejanía y la insalubridad, mantuvieron aislada a la localidad. Lo anterior contribuyó a que conservaran sus usos y costumbres, sus formas de gobierno, donde los brujos, generalmente ancianos compartían el poder con el jefe del pueblo, encargándose de organizar la vida social y religiosa de la comunidad. Para 1857, la población contaba con

1 Según Bradley (1988), los nahuas de Mecayapan debieron establecerse en la Sierra en el siglo XVI, después consumada la conquista española. Apud Velazquez (2003:9). Fueron aproximadamente 10 familias las que se establecieron según Law (1960:12). 
un palacio municipal y ya en 1870 , el poblado estaba registrado como municipio libre.

El parte aguas en la historia de Mecayapan lo es sin duda la década de los años de 1940 y 1950, cuando la producción ganadera se introdujo en la sierra y, aunque fueron pocos los indígenas que se dedicaron a la ganadería, ${ }^{2}$ esta actividad impulsó en parte la apertura de la carretera que comunica a Soteapan con Chinameca y Oteapan en 1960, lo cual abrió las puertas al comercio; asimismo como veremos más adelante, es la entrada de otras creencias distintas al catolicismo.

\section{El campo religioso local}

La presencia del catolicismo en Mecayapan, si bien se remonta desde la conformación de la población, propiciada por los franciscanos, nunca fue relevante para los nahuas. Ellos debían asistir a Chinameca 3 para escuchar misa y el sacerdote sólo los visitaba en Mecayapan en la fiesta del santo patrono y el 12 de diciembre. El catolicismo de entonces estaba mezclado con ritos y mitos cosmogónicos de los náhuas (se hacían ritos y ceremonias a la tierra, a la lluvia, a la cosecha entre otros). Es hasta 1906 que se construyó la primera iglesia en el pueblo. La capilla se levantó sobre cuatro horcones de madera y un techado de paja (Law, 1960).

La forma singular de religiosidad del catolicismo encontraba como medio de expresión las fiestas, en las que la gente manifestaba sus alegrías y tristezas por medio de las danzas, la música, los rezos, la comida y ritos asociados a sus ceremonias. De las celebraciones más importantes, cabe resaltar la fiesta del "día de muertos" y la fiesta ofrecida al Santo Patrono Santiago Caballero. Se cuenta que personas de otros pueblos venían a solicitarle buenas cosechas y toda clase de milagros asociados principalmente con la agricultura. La fiesta "Grande" dedicada a Santiago, se celebraba el 25 de Julio, pero, como era temporada de lluvias, los aguaceros deslucían la fiesta, por ello la fecha se cambió al 28 de Mayo.

\footnotetext{
2 Véase: Velázquez (1992).

3 Uribe (2002: 172) citando a Delgado (1992), señala que: Chinameca era la cabecera parroquial ya que desde 1792 abarcaba las iglesias y capillas de Jaltipan, Oteapan, Cosoleacaque, Minzapan, Moloacán, Ixhuatlán, Soteapan, Mecayapan y el área de Huimanguillo, en Tabasco.
} 
En Noviembre de 1944, llega Howard William Law, misionero del Instituto Lingüístico de Verano (ILV), con una nueva fe. Law llegó con el fin de conocer el idioma y traducir la Biblia a la lengua vernácula. Publicó un diccionario del nahua que se hablaba en ese municipio. También hizo algunas traducciones de pasajes del Nuevo Testamento y realizó una tesis de doctorado para la Universidad de Texas. Además, combinó todo lo anterior con trabajo evangelístico entre los pobladores. "El gringo" -como le llamaban- llegó primero a vivir en casa de Don Víctor C, agricultor y ganadero del lugar. Pasado un tiempo, Law alquiló un terreno donde construyó su propia vivienda y se dedicó a hacer amistad con algunos lugareños. Por las tardes ponía a funcionar fuera de su choza un tocadiscos de baterías, porque entonces todavía no había luz en el pueblo, con lo que llamaba la atención y curiosidad de los que pasaban, acercándolos a él. La comunicación con los indígenas fue difícil al principio, pero la habilidad con la que aprendió el nahua le ayudó a conversar con ellos. Su red de relaciones creció y de entre la gente que lo visitaba (Víctor C., Crescencio S., Nicasio S., Patrocinio L., Genaro R., Bartolo H., Demetrio G., entre otros) escogió a 7 personas que fueron los que le servirían como informantes para su conocimiento de la lengua y como grupo de líderes para llevar a cabo el trabajo evangelístico.

Para los habitantes eran extrañas las actividades del forastero, tanto, que corrió el rumor de que "el gringo" había traído un Santo Negro al que le rezaba;4 la curiosidad atrajo a los indígenas hacia el extranjero y éste aprovechó la ocasión para mostrarles "un libro negro" que no era otra cosa que la Biblia. En éste, les decía, iban a encontrar la manera de resolver sus problemas de salud, vivir en armonía y paz. Alejados de los servicios de un médico, los indígenas a veces le pedían medicamentos o, cuando el caso era grave, que los transportara a la clínica-hospital de la ciudad, porque era la única persona del lugar que poseía una camioneta. A él se acudía lo mismo por una ayuda económica que por un consejo. Todo lo anterior le ganó la simpatía y confianza de la gente, lo que aprovechó para repartir entre ellos varios ejemplares del Nuevo Testamento e invitarlos a su lectura. Por las tardes se reunía con ellos para estudiar la Biblia y explicarles aquello que no comprendían. Aunque en los 10 años que estuvo en

\footnotetext{
4 Según testimonios, antes de la llegada del misionero, los pobladores eran muy asiduos a practicar la magia negra y por ello pensaron que el misionero traía una nueva práctica de magia negra.
} 
Mecayapan él no formó ninguna agrupación religiosa, si conformó el grupo pionero que posteriormente conformaría la iglesia pentecostal Eben-ezer.5 De dicha iglesia habrían de salir los líderes de las agrupaciones religiosas que se establecieron en otros poblados nahuas

El misionero no proyectó adscribirse a ningún grupo evangélico de los ya formados en ciudades cercanas a la localidad, pues él sólo quería que la Biblia fuera estudiada por los lugareños. Dentro del grupo con el cual compartía los estudios bíblicos, había brujos que sabían magia negra, curanderos, alcohólicos y gente que había participado muy de cerca en las fiestas del Santo patrono. Al darse la conversión religiosa de estas personas, claves en la organización de las festividades católicas en Mecayapan, y ante la falta de visitación del párroco, el catolicismo se desplomó, provocando que la gran mayoría de las personas viera en el grupo pentecostal la sustitución de su creencia. Pero a medida que el grupo se consolidaba, el misionero dejó todo en manos los lugareños. Algunos dicen que tomó la decisión de irse porque sus hijas estaban creciendo y los jóvenes indígenas andaban enamorándolas, y él no quiso que sus hijas se quedaran en ese lugar.

Al mudarse Law, los recién evangelizados buscaron el apoyo de pastores en San Andrés Tuxtla quienes les ayudaron a organizarse como iglesia. Dentro del proceso de organización y conformación de la iglesia eligieron entre ellos a Crecencio Salas, para que fungiera como pastor, quizás en la elección tuvo que ver el hecho de que en su casa se llevaban a cabo los cultos. Pero pasado este tiempo de organización, decidieron construir la iglesia en el sitio a donde ahora se encuentra. Para ello, Crescencio Salas, decidió junto con los demás, pedir apoyo de la iglesia Eben-ezer de San Andrés Tuxtla, perteneciente a la Unión de Iglesias Evangélicas Independientes en la República Mexicana, la cual tiene seis secciones en varias partes del país. Esta agrupación religiosa los apoyó en los trámites y en la construcción del templo, y es a la que ahora deben informar de sus actividades. Además, esta el misma organización religiosa se encarga de remover y mandar pastores a los lugares que ellos juzguen pertinente; a ayudarlos en situaciones difíciles en cuanto a organización y conducción espiritual, por ejemplo, como sucedió con la destitución de un pastor por

5 La iglesia Eben-ezer se estableció como iglesia pentecostal el 12 de noviembre de 1956 por el señor Crescencio Salas Bautista en el Barrio Primero. 
problemas de índole moral. ${ }^{6}$

En los años de 1970, la edificación del templo Eben-ezer en la cabecera fue todo un acontecimiento que solidificó a la agrupación pentecostal, se establecieron misiones en varias partes de la región, que crecieron muy rápidamente, edificando lugares improvisados para las actividades cúlticas. $\mathrm{Al}$ interior de la iglesia pentecostal había una gran actividad. Se cuenta que por ese tiempo se vivía una euforia inusitada, todos querían saber qué se decía en la iglesia pentecostal, tanto dentro de la localidad como fuera de ella; la gente no hablaba de otra cosa que no fuera del evangelio. Cuando por primera vez tuvieron luz ${ }^{7}$ y se empezaron a comprar grabadoras, las casas donde había estos aparatos no dejaban de escucharse a todo volumen cánticos evangélicos a todas horas del día.

Los católicos que se resistieron a entrar al evangelio prácticamente estaban confundidos y absortos sin saber qué hacer ante tal frenesí que se vivía en la localidad con la actividad de la iglesia evangélica que levantaba misiones no sólo en el propio municipio sino en los municipios cercanos. En cambio la actividad católica sólo se veía en la fiesta del Santo patrono, en semana santa y en la navidad y año nuevo. Las visitas del párroco que antes eran por lo menos una cada mes, se fueron espaciando, debido a que éste les decía que. "a qué venía si la gente era muy poca y todos se habían vuelto evangelistas". Lo anterior desalentó a los católicos y sólo unos cuantos permanecieron fieles, concentrándose alrededor de la devoción del santo patrono.

Pese a que la iglesia católica fue construida antes que la iglesia pentecostal Eben-ezer, al quedarse sin sus principales activistas, se paralizó en su desarrollo. Este hecho se puede evidenciar en su construcción, la cual se quedó postergada hasta la actualidad.

Los líderes que había dejado el misionero Law, a medida que la iglesia Eben-ezer se desarrollaba y difundía por la región, iban cada vez especializándose en ciertas actividades y conocimientos bíblicos. Unos empezaron a entender de diferente manera los versículos de la Biblia, por

\footnotetext{
6 Cuando muere Crescencio S. (fundador de la iglesia pentecostal), su hijo Juan S. lo sucede por decisión unánime tanto de la sección de la organización de estas iglesias pentecostales, como de la misma congregación de Mecayapam, pero este último, después de unos años fue acusado de adulterio.
}

7 La luz se introduce en 1970 al poblado. 
ejemplo en lo referente al bautismo ${ }^{8}$ a otros les gustaba más predicar sobre el antiguo testamento, que sobre el nuevo testamento; a otros les gustaba más la alabanza y menos la evangelización y la predicación. Lo anterior, llevó a que el grupo fundador empezara a tener diferencias especiales que provocaron que algunos de ellos buscaran la forma en que ellos podrían satisfacer sus propios intereses. Fue así como algunos de ellos se fueron separando de Eben-ezer, algunas veces apoyados por gente de fuera de la localidad que conocían en sus estancias laborales hacia otros municipios 9 o bien, apoyados por gente perteneciente a otras iglesias que venían a la localidad. Tal fue el caso del profesor Marcelo V. El profesor impartía su clase en la cabecera municipal y hablaba con la gente sobre la necesidad de llevar con más firmeza el compromiso religioso Para ello, el Sr. Genaro R. uno de los 7 que estudiaron con Law inicialmente, se motivó mucho con el profesor y decidió salirse de la iglesia Eben-ezer, junto con Demetrio, a quien no le pareció que uno de los miembros se separara de su mujer y se buscara otra. Los tres deciden erigir un templo en la Calle Díaz Mirón en el Barrio Cuarto. Por su forma de culto y organización se debe pensar que estamos ante una iglesia neopentecostal, donde se resalta mucho la teología de la prosperidad y la salvación individual. A la fecha la iglesia se encuentra en construcción, su nombre es Iglesia Cristiana Evangélica Espiritual y tiene su matriz en Monterrey N. L. desde donde nombra al pastor de la congregación, que al principio fue Genaro R. Actualmente la iglesia Cristiana Espiritual tiene 150 feligreses. La diferencia con Eben-ezer se da en los compromisos y la liturgia más rígida y controlada por el pastor, en las normas y principios muy estrictos, "por ello, el que no puede cumplir mejor opta por salirse.” Según sus miembros.

Cabe mencionar que de esta agrupación han salido varias misiones de esta misma denominación religiosa. Los cultos se realizan al igual que los de Ebenezer todos los días de las 6 a las 8 de la noche.

A decir de los mismos creyentes, las dos creencias son buenas, la primera porque es la madre de la cual salen, pero desgraciadamente se corrompió debido

8 Genaro R. entendió lo del bautismo como lo expresa el apóstol Pedro en Hechos 2:38 en donde el bautismo trae consigo el recibir el Espíritu Santo y en cambio Crescencio S. entendía el bautizo como lo expresa Mateo 28:19.

9 Es útil mencionar que en la década de 1970 mucha gente de Mecayapan salió a trabajar en la construcción de la refinería de la Cangrejera (Entrevista con Fco. Hernández). Véase también Uribe (2002: 91). 
a la falta de entrega y compromiso fiel tanto de los creyentes como de sus dirigentes, además de que carecen de un conocimiento profundo de interpretación bíblica. En cambio para los de la iglesia Eben-ezer, los de la Iglesia Cristiana Espiritual son: "unos exagerados" e incluso "fanáticos", "que intentan seguir la Biblia sin fijarse en el tiempo que ahora vivimos", Si bien hay este tipo de comentarios de ambas creencias, en la interacción social en la localidad ambos creyentes se saludan y respetan evitando hablar sobre quien es mejor. Para los católicos, los evangélicos son "personas que nada les calienta, por eso es que constantemente se dividen." Para las personas de otras iglesias evangélicas y personas de otros grupos como los Testigos de Jehová, ambas iglesias son buenas, pero sí reconocen que en una hay mayores problemas que en otra, ambas son escandalosas y gritonas, según los adventistas y bautistas.

Las divisiones en Eben-ezer siguieron dándose en la medida en que también sus feligreses iban creciendo. Algunos líderes empezaron a sentirse incómodos y mejor se salieron llevándose a algunos miembros con ellos, básicamente sus familias, tal fue el caso de Calixto M. quien funda la iglesia Cordero de Dios, pentecostal independiente. Fue hasta 1994 que erigieron un templo en la localidad apoyados por la iglesia matriz que se encuentra en Acapulco Guerrero. El hecho de que esta iglesia haya llegado a Mecayapan fue que Calixto M. estuvo trabajando por Guerrero por seis meses y, teniendo la necesidad de congregarse en una iglesia, entró a esta. Allí les platicó a los encargados la necesidad que había en su localidad de la "palabra de Dios". Después de acompañarlo varias ocasiones para ver si era factible la ayuda a Mecayapan, la iglesia pentecostal de Guerrero decidió apoyar a Calixto, en la apertura de la iglesia. Calixto prestó el espacio para llevar a cabo los cultos y una persona que venía de Guerrero lo asistía cada 15 días. Primero la llamaron "Jerusalén", luego "El Pastor" y en 2001 a la llegada de un nuevo encargado, le pusieron el actual nombre "Cordero de Dios". Se ubica en el Barrio Cuarto en un salón de material con madera. Tiene 25 feligreses. Los cultos los tienen a la misma hora que las iglesias anteriores. Los miembros de esta iglesia aseguran que son iguales a las iglesias Eben-ezer y la Evangélica Espiritual, que incluso no tienen ningún problema en asistir a una u otra, pero que prefieren hacerlo en "Cordero de Dios" porque allí sí les prestan atención y pueden participar y trabajar mejor en la obra evangelística además porque son familias. 
Otra congregación religiosa que se desprendió de la iglesia Eben-ezer fue la iglesia fundada por Ernesto M. Esta Iglesia se creó como una sucursal y se lo hace por la necesidad de algunos de sus miembros que viven retirados de la iglesia y de noche les es difícil asistir. La iglesia lleva por nombre "La voz que clama en el desierto", no tiene pastor y posee 20 miembros. Quienes dirigen son laicos de Eben-ezer y familiares de don Ernesto M. La cual se constituyó el 18 de diciembre de 1999. Los cultos se realizan todos los días en el Barrio Cuarto a las 7 de la tarde. La iglesia está construida de madera y de cartón.

En 1970, se formó la iglesia “Jehová Jireh” por Lucas L. quien pertenecía a la iglesia de Eben-ezer, pero al tener una revelación por medio de un sueño, donde se le indicaba que debía establecer una nueva iglesia, éste decidió, juntamente con su familia, separarse de Eben-ezer y cumplir con la revelación dada. Actualmente esta iglesia tiene 15 miembros que se reúnen en el Barrio Segundo. No tienen ninguna relación aparentemente con ninguna otra organización religiosa local ni extralocal y ponen mucho énfasis en el tiempo apocalíptico que ya se está viviendo. Los cultos son a las 7 de la tarde los días miércoles, viernes y domingos Lucas L. es quien dirige todo.

Otra agrupación más a que dio lugar Eben-ezer fue la iglesia Pentecostal Israel, fundada el 14 de diciembre de 1986 por Bartolo H., quien se había convertido en Eben-ezer después de ser un alcohólico empedernido. Bartolo, preocupado por una enfermedad incurable que tenía su hermano, buscó ayuda y apoyo en oración en Eben-ezer, pero aquí nunca "se obró el milagro", pero al concurrir a la iglesia pentecostal independiente en Soteapan fue sanado. En agradecimiento donó un pedazo de su solar de 10 x 20 para la edificación de un templo ubicado en el Barrio Primero, donde él es el encargado de 40 feligreses. Los cultos se realizan todos los días de 6 la tarde. La iglesia es de concreto y pertenece a la iglesia pentecostal independiente "Rey de Reyes" con distrito en Soteapan. En esta iglesia se pone mucho énfasis en “campañas de sanidad”, son cultos especiales a las que asisten personas que tienen el don de la sanación a través del Espíritu Santo. Estas campañas sólo se realizaban una vez al año porque no tenían recursos para llevarlas a cabo más frecuentemente. Tampoco contaban con pastor, viene un laico a darles el mensaje.

Similar historia ocurrió en la formación de la iglesia "Vida Victoriosa" también pentecostal, fundada el 2 de agosto de 1993 por Luis B. La iglesia se 
encuentra en el Barrio Segundo. Aquí fueron los feligreses de la iglesia pentecostal de Coatzacoalcos los que motivados por el pastor Isidro V. realizaron la construcción todavía inconclusa de la iglesia. Actualmente son 8 feligreses (2 familias) y pese al corto número de miembros, la iglesia continúa existiendo. Los cultos se realizan toda la semana a las 7 de la tarde. La iglesia no tiene pastor de planta y únicamente los visita el pastor Isidro V. cada mes. Entre semana son los familiares de Luis B. quienes se encargan de los cultos. La motivación de crear esta congregación fue a partir de una sanidad que recibió en la ciudad de Coatzacoalcos su fundador, el cual llevaba con esta enfermedad más de veinte años. Al ser aliviado por una oración milagrosa de sanidad en la iglesia pentecostal, Luis B. hizo la promesa de servir a Dios en el lugar donde vivía $\mathrm{y}$, sin saber leer ni escribir, se propone la tarea de evangelizar en Mecayapan ayudado por su familia.

Otra iglesia más que emerge de Eben-ezer fue la que fundaron en 1994 las señoras Ruth P. y Natalia C., denominada Bethel. Estas mujeres visitaban frecuentemente la localidad, venían desde Minatitlán de una iglesia pentecostal de esa ciudad. Actualmente hay un laico que viene de esa ciudad a organizar la actividad cúltica, la cual se lleva a cabo los martes, jueves, sábados y domingos a las $6(\mathrm{pm})$ de la tarde. El pastor va y viene desde Minatitlán los días de culto. El templo donde se realizan los mismos es una choza improvisada para los cultos que se construyó en 1999. Actualmente tienen 10 miembros y frecuentemente reciben visitas de la iglesia madre de Minatitlán. La iglesia nació de la invitación que un miembro de esta iglesia urbana hizo a un joven de Mecayapan, el cual al convertirse y regresar a Mecayapan convierte a su familia animándolos a formar la misión ahora iglesia en el Barrio Cuarto.

También de corte pentecostal es la iglesia "Príncipe de paz," que sale de que formó Lorenzo L. en 1960, "El Buen Pastor" (más adelante hablaré de ella), quienes primeramente trataron de hacer alianza con otra iglesia en la localidad, pero, como no hubo acuerdo y después de estar en contacto con iglesias fuera de la localidad, decidieron añadirse como misión de una iglesia pentecostal del mismo nombre en Coatzacoalcos en 1999. Actualmente tienen 27 feligreses. Se localiza en el Barrio Segundo. Las reuniones se realizan los miércoles, viernes y domingos a las 7 de noche. Aunque no cuenta la iglesia con pastor de planta, Lorenzo, nativo del lugar, es quien dirige las actividades cúlticas. En la 
temporada de campo los miembros estaban analizando si se quedan con los pentecostales de Coatzacoalcos o se cambian, ya que no es constante el misionero que viene de la ciudad y ellos piensan que así no va a crecer la membresía.

Una más de las iglesias pentecostales que se formaron recientemente, en 2002, pero que su origen se remonta desde 1985, es la iglesia "Monte de los Olivos", fundada por Patrocinio L., el cual asistía a Eben-ezer, pero en 1987 se cambió para la iglesia de La luz del Mundo, no obstante, por razones de que no podían ir a Guadalajara a las festividades anuales que se celebran ese lugar, renunciaron al movimiento y para 1988 buscaron aliarse con la iglesia Apostólica de la Fe en Cristo Jesús de Minatitlán, pero debido a las pocas aportaciones económicas, la iglesia Apostólica los abandonó, Patrocinio buscó el apoyo de otras iglesias en Coatzacoalcos y encontró a la iglesia de Bethesda, una iglesia pentecostal independiente cuya matriz nacional está en Aguascalientes. De Coatzacoalcos va un laico a apoyarlos en la actividad cúltica donde se reúnen 33 personas en el Barrio Primero.

Si observamos los motivos por los cuales se desprenden estas nuevas congregaciones de la iglesia Eben-ezer, son por encontrar sanidad, por la labor de evangelismo de otras iglesias pentecostales que hay en la región, principalmente en los lugares de trabajo, y por revelaciones. Pero no sólo las iglesias de corte pentecostal han sido las que han podido incursionar a la localidad, también se encuentran iglesias que no tienen muchas semejanzas litúrgicas con las pentecostales como lo es la Iglesia Adventista del Séptimo Día cuya liturgia, organización e interpretación bíblica difiere de los pentecostales. ${ }^{10}$

Se tiene el caso de la iglesia adventista, la cual también salió de la iglesia Eben-ezer. Su origen, según cuentan miembros de esta congregación, fue cuando el señor Macario B. del Barrio Cuarto, después de nueve años de asistir a Eben-ezer, decidió en 1974, abandonar el pentecostalismo por considerar que esta iglesia le faltaba llegar a la verdad. Todo empezó cuando su hermano estando trabajando en Oaxaca le envió una Biblia. A partir de entonces, empezó a estudiarla y se dio cuenta de algunas interpretaciones equivocadas que se decían en la iglesia Eben-ezer, lo cual aunado a la indiferencia de los líderes de

10 Por cuestiones de espacio, no me meto en aspectos doctrinales, sirva solo saber que uno de los puntos centrales de esta denominación religiosa lo es el día sábado, "como día de reposo", así como ciertas restricciones alimenticias. 
esta iglesia decidió retirarse. Al verse solo y abandonado completamente por los del grupo Eben-ezer, Macario cayó en el alcoholismo y una gran depresión, como él tenía una necesidad muy fuerte de conocer "la verdad en la Biblia" se acercó con unos adventistas de Chinameca, quienes le explicaron detenidamente todo lo que no entendía de la Biblia, la cual no dejaba de estudiar. Los miembros de la iglesia adventista de Chinameca al ver su interés y fidelidad en el estudio bíblico, decidieron invitarlo a iniciar la obra evangelística en Mecayapan, él aceptó sin titubear. El nombre del templo es "Iglesia Adventista del Séptimo Día”. A Macario se le han acercado otras personas de otras creencias pero no lo convencen de dejar sus principios religiosos en el adventismo. En un principio eran solamente su familia, posteriormente se sumaron otras vecinos suyos. Actualmente son 29 miembros los que asisten a esta agrupación. En ocasiones son más, dado que frecuentemente reciben visitas de las iglesias adventistas de la región y de lo que ellos llaman el distrito de Chinameca. Los días de culto de la iglesia son los miércoles, viernes, sábado y domingo a las 7 de la tarde. El sábado hay un culto a la nueve de la mañana y a las doce del día y al atardecer.

Existe otra iglesia adventista en la localidad de Mecayapan, pero ésta no surgió de la adventista anterior, sino de la adventista que se encuentra en Huazuntlán. Esta iglesia se encuentra en el Barrio Cuarto. Fue fundada en 1993 por Francisco H. y Alicia H. después de un acto milagroso que consistió en la sanación de su hijo, el cual al verse enfermo fueron a Huazuntlán con una persona que tenía una farmacia e inyectaba y era adventista. El sacó su Biblia y les dijo: "vamos a recitar salmos". Después se pusieron de rodillas e hicieron oración por el enfermo, cuando se levantaron cantaron tres himnos y después les dijo: "ahora sí, ya le voy a poner la inyección al enfermo, pero primeramente nuestro señor Jesucristo que ponga su mano en este niño. Para mañana, -nos dijo-, el niño va a estar sano". Al amanecer, a las 5 de la mañana, el niño estaba sano. El adventista les dirigió de esta forma la palabra: "vieron hermanos ésta es la maravilla de Dios, el niño ya está sano”. Después de este milagro les platicó acerca de la palabra de Dios, ellos le dijeron que eran "del pentecostés", pero él no le dio importancia y les habló sobre cómo se guardan los mandamientos de Dios. Al terminar la plática les dijo que pensaran en lo que habían platicado. Ellos estaban confundidos, pues en la iglesia Eben-ezer habían sido convertidos 
y sabían que allí también se operaba el milagro a través del Espíritu Santo. Reproduzco a continuación la entrevista de Alicia H. cuando toma la decisión de cambiar de iglesia.

Mi esposo y yo platicamos, yo le decía, ¿cuál es el mejor camino que vamos a escoger? Dice: pues quién sabe, yo estoy bien confundido, dijo: dejamos el pentecostés y mejor vamos a ir en el séptimo día. Porque, dice: el mandamiento, si no lo guardamos el séptimo día, conforme el mandamiento como dice el señor Jesucristo, no somos nada. A los pocos días vino el hermano de Huazuntlán y nos dijo "ora hermanos qué piensan ustedes", y le dijimos, pues, nosotros estamos confundidos, le digo, porque nosotros queremos participar en Iglesia Adventista del Séptimo Día. Pero no hay iglesia aquí, hay pentecostés y del evangelio. Él nos dijo: si quieren ustedes participar en la adventista, vamos a fundarla aquí en tu casa, Al siguiente sábado hicimos culto aquí en mi casa.

Actualmente la iglesia tiene 26 feligreses. Asisten principalmente los sábados en la mañana de 9 a 12 y en la tarde después de las 6. Tanto esta iglesia como la anterior adventista no se juntan una con la otra, ya que son fieles a sus matrices quienes los han apoyado en la formación de su agrupación. Cuando les pregunté que opinaban de las demás iglesias, me contestaron que los creyentes de otras iglesias conocen la verdad, "pero a medias", ya que la verdad suprema está en la Biblia y que para ello, "es necesario leerla e interpretarla como debe ser".

Otra surgió de miembros de la iglesia pentecostal Eben-ezer que fundaron una iglesia adventista en este mismo barrio. El pastor Serafín, originario de Chinameca, es quien la atiende. El templo se fundó 4 años después de que Macario fundara el primer grupo de adventistas en este lugar en 1978. Esta iglesia realiza sus cultos los días viernes a la puesta del sol, momento en el cual empieza el "día de reposo". El sábado por la mañana a las 9, se tiene un culto que termina a las 12, luego el domingo y miércoles a las 7 de la tarde. La matriz de esta iglesia se encuentra en Catemaco. Sus miembros son 10 y está compuesta por una sola familia. Esta familia se separó de Eben-ezer al no ser visitados y atendidos por los líderes de esta iglesia. Al venir el Pastor Serafín desde Chinameca a evangelizarlos, les pareció muy interesante su prédica y decidieron recibirlo en su casa y establecer la obra misionera de esta iglesia adventista en este lugar. Ellos sólo le proporcionan el pasaje y la comida y el pastor viaja cada vez que hay actividad cúltica.

Las iglesias adventistas se caracterizan por ser muy celosas de la tradición judía, en cuanto a su alimentación, rituales e interpretaciones sobre como 
iniciar y guardar "el día de reposo". Cuando pregunté a un miembro el porqué no se juntaban las tres adventistas en una sola, me contestó: "cada iglesia tiene su forma y estilo de llevar a cabo su ritual y sus costumbres, unos nos apegamos más a la escritura (la Biblia) y otros a costumbres y rituales no bíblicos." Los adventistas señalan que: "es posible que un Católico o no católico se vuelva adventista si busca la verdad, pero es poco probable que un adventista una vez que ha conocido "la verdad" se convierta a otra religión, es más, ni siquiera se pasa con los demás adventistas de los otros que hay aquí, mejor se está sin religión". Si observamos los motivos por los cuales se separan de la iglesia Ebenezer, son diferencias por: la interpretación equivocada de la Biblia, por el conocimiento bíblico que ellos van adquiriendo y que les hace "abrir los ojos" y por la labor evangelística que ellos mismos emprenden, así como por actos milagrosos.

Una de las iglesias más antigua es la iglesia "El Buen Pastor", ubicada en el Barrio Segundo. Se fundó en 1962 por Marcelo V. de Acayucan. Él empezó a predicar el evangelio en la localidad. Al inicio la iglesia fungió como una iglesia Bautista en la concepción religiosa trinitaria (creían en Dios Padre, Dios Hijo y Dios Espíritu Santo). Posteriormente, debido a que el misionero dejó de ir, César D. se encontró a unos misioneros de la iglesia Apostólica de la Fe, la cual es unitaria (solo creen en que existen un solo Dios y no tres personas como lo piensan las iglesias trinitarias). Por lo que, después de tres años de haberse fundado la congregación, en 1965 la iglesia cambia su postura teológica trinitaria por una teología unitaria. El templo donde realizan el culto se construyó hasta 1972, con la cooperación de los feligreses, apoyados por los amigos del misionero bautista. Esta iglesia no pide diezmo a sus feligreses ya que consideran que no hay trabajo en la localidad y que sería un sacrificio el pedirlo como lo hacen principalmente las pentecostales y adventistas. Tampoco llevan a cabo campañas evangelísticas como los pentecostales y los adventistas. Ellos solo tienen culto los domingos de 10 de la mañana a 2 de la tarde. La persona que los atiende viene desde Coatzacoalcos y es miembro de una congregación Apostólica de ese lugar. Son 12 miembros, que estudian la posibilidad de cambiarse de religión ya que el misionero que viene a "ministrarles" no les cae bien, por inexperto y no conocer el sentir de la gente de Mecayapan. Algunos han considerado, incluso, volver a Eben-ezer, sólo que 
estos últimos no les han prestado atención. ${ }^{11}$

Otra iglesia que se ha formado a partir de noviembre del 2000 es la iglesia de Dios de la profecía, la cual se ubica en el Barrio Cuarto, Sus cultos se realizan el domingo al medio día. Las personas que se reúnen son 20. Las reuniones las hacen bajo la sombra de un árbol en medio del patio de su casa, improvisando con sillas y tablas se forma el espacio de adoración cultica. Los cultos se llevan a cabo en la casa de Victoria H. Las reuniones se llevan a cabo con constancia, son 12 miembros. El que trajo esta creencia religiosa fue Víctor M., amigo de la familia de Victoria. No hay una organización formal, la familia abre sus puertas de su hogar para que sea predicado el evangelio. No tienen nombre todavía. Los cultos son los domingos por la tarde a las 6 .

También fue incorporada la iglesia de la "Luz del Mundo". Gonzalo H. fue el que la trajo. Él vivió en Acayucan por algún tiempo y fue convertido a esta agrupación y los dirigentes de esa iglesia decidieron establecer una misión en este lugar. Su membresía es de 25 a 30 miembros y fue en 1999 cuando se erigió su templo en este lugar, su liturgia y organización es muy parecida a la de los templos pentecostales que existen en la localidad. Tienen un pastor que realiza la actividad cúltica todos los días de la semana a las 7 de la tarde, excepto el domingo que es por la mañana y por la tarde.

Igualmente se encuentra también actividad religiosa en hogares llamados "grupos de estudio", que se lleva a cabo con personas que han aceptado estudiar la Biblia con los Testigos de Jehová que vienen de Chinameca. Hubo algunos lugareños que me aseguraron que también hay simpatizantes de otros credos religiosos como La Institución Divina de la Profecía. En el 2001 hubo los judíos, se sabe que hay seguidores de William Soto Santiago. De la iglesia "Galván" que en mi temporada de campo no los pude contactar.

Lo que más asombró me causó como antropólogo fue por las noches después de las 7 horas y especialmente en domingo (y ya no se diga en festividades de semana santa o navidad), ver la cantidad de cultos religiosos que tienen efecto en la localidad. Me sorprendió como uno puede estar participando de la liturgia en un lugar y en frente de ese domicilio ver cómo se lleva a cabo

11 Seguramente, casos como el que se describe pueden haber aparecido y desaparecido sin que hayamos podido registrarlos. Incluso, casi la mitad de las agrupaciones que se describen en este trabajo no están legalmente reconocidas como lo establece la Ley de Asociaciones Religiosas y Culto público establecido en 1992 por la Federación. 
otro acto cúltico de otra agrupación religiosa, escuchar los cantos de los que a lado se encuentran cantando con frenesí, prestar oídos a los cantos o predicaciones por los altavoces de las iglesias Eben-ezer o Cristiana Evangélica Espiritual, escuchar la campana de la iglesia católica llamando a misa o a los rosarios. Obviamente que quienes resaltan más por su forma litúrgica son los pentecostales. Son ellos, hasta ahora, los más agresivos en cuanto a la labor evangelizadora al dormir y al despertarme siempre oía música cristiana en las diferentes grabadoras que tienen las familias en sus casas, con cantos que se repiten una y otra vez como una manera de llamar la atención e invitar a la gente a poner atención al canto.

Al ver tanto desbordamiento de actividad y diversidad religiosa me surgieron las siguientes interrogantes sobre este fenómeno: ¿Qué es lo que los lugareños buscan en estas agrupaciones religiosas? ¿Porque existen tantos grupos religiosos, que ha motivado esta diversificación? ¿Cómo es que habiendo tanta fragmentación no se den conflictos en un espacio tan reducido? ¿Cómo marca tal diversidad de creencias la conformación de la identidad de la localidad y cuáles son los efectos? Estas preguntas guiarán el análisis en el siguiente apartado.

\section{La coexistencia religiosa en Mecayapan}

Las agrupaciones religiosas descritas anteriormente pueden comprenderse en dos categorías: Unas que llamaremos del grupo A, compuestas por miembros que tienen un pastor, sacerdote, líder afiliado a una iglesia matriz generalmente fuera de la localidad en las ciudades cercanas, que a la vez pertenecen a organizaciones religiosas establecidas a nivel nacional y/o regional. Por lo general son las agrupaciones más antiguas en la localidad como lo son: la iglesia Católica, la iglesia Eben-ezer, la iglesia Cristiana Espiritual, algunas iglesias pentecostales y adventistas, que cuentan con un pastor o encargado ex profeso para tal acción de cuidado y mantenimiento de la agrupación, de ahí que haya un especial preocupación en la socialización interna local. Este tipo de congregaciones religiosas tienen que rendir un informe de actividades (anuales o semestrales) sobre lo realizado en el lugar y su organización, tienen cuerpos organizativos propios de cada organización religiosa. 
El otro grupo de agrupaciones que encontramos es el que he denominado el grupo B, el cual está compuesto por congregaciones religiosas generalmente de reciente creación (de 1980 a la fecha) que carecen de un representante oficial o encargado, aunque algunas veces tengan el respaldo o apoyo de alguna institución religiosa o miembro de alguna iglesia de fuera que los asiste de manera temporal. Sus cultos los realizan de manera autónoma, la mayoría de las veces sin ningún manual o programa, copiándose de los modelos de las iglesias de donde ellos han estado. La mayoría de estos grupos tiene un alto interés en hacer amistadas fuera de la localidad. Su autonomía en cuanto a su organización $\mathrm{y}$ funcionamiento los hace mutar o a veces cambiarse de nombre y tendencia teológica, o bien desaparecer en periodos de tiempo muy cortos.

Un aspecto central que puede observarse en ambos tipos de agrupaciones es el papel que juegan las redes familiares, como conjunto de relaciones que unen a los individuos con otras personas y con unidades sociales concretas. En ambos tipos (A y B) existe una unidad territorial, al compartir un mismo espacio étnico, una misma lengua y un mismo pasado histórico. Cada una de ellas abarca a un grupo de personas que se hallan relacionadas entre si. Generalmente las congregaciones más pequeñas están relacionadas por lazos de parentesco cercanos y las más grandes están relacionadas no solo por los lazos de parentesco más amplios, sino por relaciones económicas o políticas.

Por su forma de conformación e historia en la localidad, tanto las congregaciones religiosas del tipo A como del $\mathbf{B}$, grandes o pequeñas, viejas o de reciente creación, no fueron ni son capaces de contener a un gran número de personas en una sola agrupación religiosa, como lo fue el catolicismo en un primer momento, o la iglesia Eben-ezer por un corto tiempo en un momento posterior, ya que los creyentes desarrollaron una socialización muy fuerte intra y extra grupal, dando con ello lugar a pequeños liderazgos que luego se separan de las iglesias madres para vivir independientemente, con diversificados roles sociales, que la identidad étnica, por cierto, no les proporcionaban (pastor, evangelista, encargado del grupo); que aunado a la falta de capacidad o inexperiencia de los dirigentes de las iglesias madres, para unificar a la población de la localidad o para conciliar los intereses personales para la defensa y resolución de sus necesidades, da como consecuencia esta diversidad religiosa que ahora se vive. 
Lo religioso lejos de entrar en conflicto con lo étnico, actúa como medio por el cual el individuo intenta comprender las transformaciones de una sociedad cambiante y como mecanismo por medio del cual se logra una mejor posición en situaciones futuras de migración, crisis económica, marginación, desintegración familiar, falta de apoyo material y espiritual, entre otros.

Como observamos en la descripción etnográfica, la población optó por ser una sociedad heterogénea, pero consciente de su pasado, su lengua, así como de sus características étnicas y su modo de subsistencia común, pero con un equilibrio segmentado por lazos familiares, lealtades divergentes y opuestas. Lo anterior ha llevado a las congregaciones de tipo $\mathbf{A}$ a una concentración del poder por parte de los líderes o encargados, ${ }^{12}$ quienes planean y llevan a cabo juntamente con sus organizaciones, estrategias cada vez de más impacto en la sociedad, lo cual hace que se genere una actividad proselitista inusitada con la finalidad de allegarse el mayor número de adeptos. Generalmente, es a través de campañas evangelísticas, cultos especiales donde vienen predicadores de fuera de la localidad y que tienen el don de la "sanidad" o el don de "la palabra" y motivan a los fieles a afianzar su fe y a gente nueva a unirse al grupo.

En las agrupaciones de tipo $\mathbf{B}$, la concentración del poder se reparte entre el encargado (dirigente, laico o misionero) y los jefes de familia (generalmente los que prestan la casa o el terreno para llevar a cabo el culto) y los demás activistas del grupo. Los miembros de estas agrupaciones tienen una mayor autonomía e independencia con respecto a sus instituciones religiosas que los cobijan (no hay una exigencia de hacer planes de trabajo, informes, cierta rigurosidad en la liturgia, entre otros aspectos), pero ello no significa que no se movilicen en labores proselitistas con la finalidad de salvaguardar su status y rol en la localidad, o bien para continuar con el respaldo recibido que les otorgan a este tipo de organizaciones. La actividad proselitista se da fundamentalmente a través de los lazos de parentesco, en donde las mujeres ocupan un lugar

\footnotetext{
12 Para la mayoría de los creyentes, el pastor, el sacerdote, dirigente o líder, o incluso, el encargado de la congregación, no solo es una persona común, sino es el eje de sus relaciones sociales, el símbolo de unidad y de representación de sus valores y principios. Donde no existe el pastor o el encargado, los miembros de las agrupaciones religiosas se cobijan alrededor de sus principios y valores místicos, en sus experiencias religiosas que han tenido en la lectura de la Biblia. Lo mismo observan Fortes y Evans-Pritchard (1979: 99) en el asunto de los dirigentes africanos que guían los valores que se expresan en los símbolos místicos.
} 
esencial. ${ }^{13}$

En los miembros de las agrupaciones de tipo $\mathbf{A}$, se encuentran compromisos, obligaciones, deberes que los miembros deben de cumplir como requisito para pertenecer a la agrupación: asistencia al culto, participación en actividades litúrgicas, diezmo, estudios bíblicos, faenas, entre otras, y que si no se cumplen puede haber sanciones. En las congregaciones de tipo B, si bien hay compromisos y obligaciones, estas son un poco más elásticas, o bien, poco se llevan a cabo por falta de vigilancia de una autoridad o personal especializado encargado para llevar a cabo estas tareas; por ello, es que los deberes y las obligaciones pueden ser más laxas, o dejadas a la familia para llevarlas a cabo (a costo de perder su unidad familiar). A menudo en el tipo $\mathbf{B}$, los elementos que los unen a los miembros son: intereses comunes como el estar retirados del centro del pueblo, o porque tienen las mismas ocupaciones, actividades, horarios, o que comparten necesidades afines, o tienen lazos de solidaridad muy estrechos, entre otros.

Las características señaladas, tanto del grupo A como los del grupo B, motivan a la gente a estar unidos, a permanecer bajo ciertos valores, a guiarse con determinados comportamientos que se entrelazan sutilmente con los diversos intereses que se comparten con toda la población de la localidad.

A través de las diferentes agrupaciones religiosas es que llegué a observar cómo se vive, se piensa y se siente la población del área de estudio, cómo concibe su sistema social de forma coherente y tangible. $Y$ es que a través de estas diversas congregaciones religiosas es como los moradores pueden sentirse insertos en el sistema social y lograr la aceptación de este orden social. Que por cierto, dicho sea de paso, es más eficiente, en algunos casos, que el sistema normativo y judicial de la autoridad estatal o municipal, o el de la fuerza pública local. Pareciera como si el sistema social de la localidad, por así decirlo, fuera trasladado a un plano místico de un equilibrio segmentado de congregaciones religiosas de diversa índole, en donde cada una forma parte de un sistema de valores sagrados que no puede criticarse o modificarse. Es como si existiera un pacto implícito de coexistencia "pacifica” entre las diversas creencias. De ahí el porqué unos miembros se salgan de una agrupación y se metan a otra

13 Recomiendo al lector dos obras que muestran la importancia que las mujeres tienen en la actividad evangelística: De la Rosa (1999:115-144) y Juárez (2002). 
inmediatamente, dado que sino lo hacen estarían fuera del control social legitimado, puesto que los congregaciones religiosas católicas y no católicas se encargan de mantener a sus miembros dentro de ciertos límites, con base en las sanciones que las mismas congregaciones religiosas imponen con sus códigos de valores y principios, como por los lineamientos generales que los mantienen en coexistencia en la localidad.

Los valores que se generan en estas congregaciones religiosas son comunes para toda la población: la salud, el trabajo, la prosperidad, la paz, la justicia, en otras palabras, todo aquello que da tranquilidad y convivencia a una población. $\mathrm{Y}$ es aquí en donde las diversas congregaciones religiosas tienen un rol en la localidad, pues son la salvaguardia de las necesidades básicas de las relaciones sociales que se dan al interior de ella, de otra manera sería muy difícil obtener interacción social en su interior, salud corporal, vida familiar, tener, incluso, pertenencia a la tierra y productividad, ${ }^{14}$ preocupación constante en cada uno de sus moradores, ya que todo ello les da seguridad y esperanza. Digámoslo de otra forma, las motivaciones que llevan a los mecayapenses a generar o a aceptar agrupaciones religiosas en su localidad, son por la necesidad de actuar e interaccionar con nuevas normas morales y sociales con su sociedad y con otras sociedades básicamente de la región, especialmente de las ciudades como Coatzacoalcos, Minatitlán, Acayucan, San Andrés, Chinameca, entre las más cercanas, con las cuales estan interconectados. La evidencia y eficacia del rol de estas agrupaciones religiosas se refleja en el número que encontramos en una población de 5.000 personas y en un espacio reducido. ${ }^{15}$

Vista de ese modo la tendencia de nuestro análisis, parecería que la diversidad religiosa existente obedece a fines utilitarios y esto no es solamente así, ya que en esta diversidad y coexistencia religiosa hay interacciones sociales donde se generan, símbolos, mitos, rituales, doctrinas y se aprecian personajes sagrados que los creyentes perciben como elementos de cohesión y persistencia; como valores o capital simbólico, que los asocian más allá de un plano utilitario material, formando parte de su discurso cotidiano y su modo de vida; lo que

\footnotetext{
14 El que Santiago bendiga los campos de cultivo es una práctica que, muy a pesar de que el catolicismo haya disminuido en la localidad, no ha dejado de ser importante en la región.

15 Dentro de la normatividad que el gobierno tiene para dar permiso para llevar a cabo un culto religioso está el que no es posible la construcción de un templo cerca de otro, así como el establecimiento de cantinas u otros giros que puedan devenir en conflictos sociales.
} 
solidifica y enaltece a la familia y al grupo étnico al cual pertenecen permitiéndoles la convivencia y la trascendencia social.

Por otra parte, la visible fragmentación religiosa y la aparición de nuevas formas de interacción social que se han ido incorporando, no han provocado una fragmentación étnica ni social, por el contrario, han servido como catalizadores de conflictos, valores, significados y estilos de vida distintos, que estos grupos transforman en competencias de valores morales, espirituales, significados e interpretaciones, haciendo que la identidad étnica ya no solo se construya alrededor del acceso a la tierra, la lengua, las costumbres, sino a través de las alianzas, redes e influencias con instituciones religiosas distantes de la localidad.

Es obvio que entre esta diversidad de creencias se den luchas y competencias por reclutar el mayor número de fieles. Por ejemplo, al llegar el misionero Law y posteriormente las demás agrupaciones no católicas, se removió el poder de los brujos y curanderos así como el de los viejos del lugar. ${ }^{16}$ Otro cambio en la costumbre de los nahuas, fue la cada vez más clara separación del gobierno civil del religioso, lo cual desplazó por completo muchos cargos y funciones públicas que antes los brujos y los ancianos tenían controlados. Por ejemplo, se empezaron a ser más frecuentes las legitimaciones de las uniones de las parejas mediante el matrimonio, a través del Registro Civil en la localidad; resultando innecesaria la mediación de los brujos o los ancianos en los arreglos matrimoniales. Los no católicos, por su parte, sustituyeron la figura del brujo o el anciano por la del pastor, pues era éste el encargado de recomendar las uniones entre las parejas. Entre los curanderos, yerberos, parteras, hueseros, culebreros, se comparten oficios con los médicos y la medicina formal. ${ }^{17}$ Lo mismo ha sucedido con la práctica de la sanación cada vez más frecuente por medio de la oración, que practican los diversos grupos religiosos, especialmente pentecostales y neopentecostales, los cuales han dejado de acudir a sus antiguos curanderos tradicionales. Otro cambio que señalan los pobladores fue la

16 En el ritual de la muerte, los brujos y ancianos eran los conocedores de la costumbre, asumían el papel de rezandero y guiaban la ceremonia luctuosa. Sin embargo, al convertirse a las creencias evangélicas, la participación de estos personajes se nulificó, debido a que los ritos sobre la muerte evangélicos eran distintos.

17 A partir de 1970 conviven entre la población, la medicina moderna y la tradicional. Pero, aunque la gente prefiere iniciar su tratamiento haciendo uso de la segunda, termina por asistir al médico y cuando no encuentra mejoría. 
disminución del tequio o faena que ahora solo se hace entre familias y ya no como antes con quien fuera dentro de la localidad.

Sin embargo, todos estos cambios descritos anteriormente no tuvieron por fortuna un impacto violento que lamentar, debido en parte a los fuertes lazos de parentesco y solidaridad que como comunidad indígena han tenido; así como por la desorganización social que sufrió la localidad, por la irrupción de la carretera y la entrada del ganado, juntamente con la apertura al comercio, las instituciones de salud, que como vimos, hacen su arribo a la localidad simultáneamente con las creencias no católicas. También hay que tener presente que tanto la agrupación que formó el misionero como algunas de las diferentes congregaciones religiosas que después se formaron, tuvieron como sus primeros pastores o encargados a nativos de Mecayapan, lo cual permite que la confrontación no se sienta tan directa, pues hay respeto, redes de solidaridad detrás, que es difícil de romper o enfrentar abiertamente cuando se vive en el mismo lugar y de repente sobreviene el cambio religioso, como sucedió en la mayoría de los casos de conversión religiosa.

Pero entonces ¿dónde se da la competencia religiosa? Esta no se libra en los templos, sino entre las familias y a veces en el mismo seno familiar, donde el padre puede ser católico, la madre pentecostal y el hijo adventista y el nieto ser simpatizante de la agrupación de William Soto Santiago. Pero los pastores, sacerdotes, encargados rara vez intervienen. Es probable que se les pida ayuda o apoyo, pero ésta sólo se da básicamente a nivel discursivo, a nivel de comprensión, consuelo, "apoyo bíblico". En mi estancia en la localidad recogí disputas y pleitos ocasionados por el alcoholismo, por daños en la cosecha, daños hecho por el ganado en tierras de cultivo o en casas, disputas por conseguir mayor crédito o apoyos económicos diversos de parte de las instituciones gubernamentales; en menor medida encontré delitos sexuales, abigeato. ${ }^{18}$ Cuestión que me sorprendía, pues yo esperaba encontrar una "guerra religiosa" donde se da abiertamente la deslegitimación del adversario.

En donde quizás si pude apreciar cierto tipo de competencia religiosa abierta en la localidad fue en las reciprocidades y beneficios que cada grupo intenta ofrecer, pues los mecayapenses miden la capacidad que tiene cada

18 Incluso encontré disputas al interior de la misma agrupación religiosa, donde los miembros se disputan la práctica de los dones espirituales. 
agrupación de dar atención personal a sus miembros, otorgándoles beneficios espirituales y materiales, generalmente más de los que realmente pueden ofrecer. Es en este aspecto donde los creyentes evalúan y deciden en donde quedarse o moverse, y ello no depende de la cantidad, sino de la calidad, comprensión y atención que se brinda que no es fundamentalmente material, sino de consuelo y apoyo espiritual; tampoco depende la doctrina o teología sustentada, sino de la capacidad y eficiencia que tiene la congregación de dar apoyo y ayuda en el momento preciso y adecuado a la necesidad apremiante.

\section{Reflexiones y tendencias}

En primer lugar hay que advertir la impresionante adaptación cultural que ha dado cabida a todas estas expresiones religiosas que se manifiestan en diversos agrupaciones religiosas representados por familias que tienen un jefe, muy parecido a los que señala Marshall Sahlins (1979) para los polinesios y melanesios. El jefe de la familia, juega un papel muy importante en el surgimiento y adhesión a estas agrupaciones religiosas, ya que la conversión se da en racimo; pues al convertirse o experimentar un milagro el jefe de familia, lleva consigo a todos sus hijos ya sea formando un nuevo grupo, o bien, pasando de una agrupación a otra.

Por otra parte, es útil que tengamos presente que la fragmentación de la sociedad en agrupaciones religiosas, si bien representa algunas dificultades para comprender y organizar a la población para la consecución de fines colectivos amplios, también es cierto que, a través de las agrupaciones religiosas, se logran establecer relaciones de lealtad y obligación por parte de un número corto de personas y, con ello, lograr obtener mayor eficacia en el control y respuesta así como reciprocidad y equidad en la distribución de recursos. Cualquier programa o política pública que no tome en cuenta este tipo de conformación de la población, difícilmente accederá a tener el logro deseado.

Asimismo, es relevante resaltar el papel que juegan en la organización social, la agrupación religiosa y la familia, como elementos básicos a través de los cuales se organiza la actividad social. Una y otra se dan fuerza entre si, para retener a sus miembros y atraer a más de ellos, asignándoles lealtades y compromisos, proponiéndoles estrategias de subsistencia y permanencia tanto 
dentro de la localidad como fuera de ella. Es muy importante señalar que las economías familiares, son quienes sostienen y apoyan cada una de las actividades que las agrupaciones religiosas realizan para su permanencia y desarrollo. Quizás, aquí debemos buscar las causas del porqué algunas de ellas mantienen una relativa inestabilidad y fluctuaciones que las hacen incluso desaparecer como ha sucedido especialmente con las del grupo B..$^{19}$

Por otra parte, se esperaría que esta dinámica religiosa que mantiene ocupados a la mayoría de los pobladores de la localidad generara efectos homogéneos en la dinámica social y política de la vida en la localidad. Pero esto no se da así, ya que la mayoría de los creyentes, en especial los no católicos, buscan equilibrar la escasez de recursos con el enriquecimiento espiritual y poder sobrevivir. Si bien, con una vida comunitaria intensa que genera un capital simbólico y social prometedor a nivel micro y cotidiano, pero que se manifiesta cada vez más fragmentada y con un papel todavía muy pobre en la dinámica social y política. ${ }^{20} \mathrm{Si}$ uno pregunta a los creyentes, fundamentalmente pentecostales y adventistas, cuál es su preocupación básica, la contestación más común será: "el no perder su relación directa con Dios", por lo que evitan la política pero no la participación ni el compromiso público y el mejoramiento de su sociedad, en la cual quieren influir básicamente por medio de su testimonio en torno a su conversión religiosa.

Estamos ante una forma inédita de manifestar la recomposición de la comunidad indígena, sus estrategias de reproducción social, la reconstrucción y recuperación de sus identidades étnicas, ${ }^{21}$ así como de expresar el grado de diferenciación y crecimiento demográfico y la crisis de la comunidad tradicional. Pero además, nos encontramos ante la expresión de una nueva forma de coexistencia a partir de otras formas y mecanismos de cohesión que ya no son el

\footnotetext{
19 La migración ha sido un factor esencial en la desintegración y recomposición familiar, que repercute fuertemente en las actividades que programan las diversas agrupaciones religiosas.

20 Para ampliar este aspecto el lector puede recurrir a Vázquez (2005).

21 Giménez (1993: 43) señala que junto con el desarrollo de una cultura de mayor sincretismo y con una estructura social de creciente burocracia, se ha provocado como reacción la necesidad de "anclajes" más particulares y primordiales para la identidad, la gente -señala-quiere pertenecer a menores unidades sociales y buscar el apoyo de "comunidades emocionales" de tamaño reducido. "[...] Las identidades tienden a achicarse, a reducirse y a replegarse nuevamente hacia formas más tradicionales, que creíamos superadas; se condensan en espacios próximos, se territorializan, se concentran en comunidades empáticas, reales y tangibles (y no ya en imaginarias, como la nación o el 'cuerpo místico' religioso), en fin, redes neotribales de sociabilidad."
} 
trago, la fiesta, la tradición o "el costumbre". Ante nuevas formas de identidad que ya no se definen únicamente por lo étnico, sino por lo religioso. Ser indígena, y ya no ser católico, representa un cambio en la cotidianeidad, en la percepción del mundo y estilos de vida, que muchas de las veces puede provocar una doble discriminación, pero que también puede significar para los actores sociales formas vitales de sobrevivencia y coexistencia social.

El indígena contemporáneo ya no es aquél campesino que Wolf (1970) dibujara, atrapado en la red de sus lazos familiares y comunales, que le servían de defensa frente al exterior. Hoy lo vemos transitar del campo a la ciudad, de una religión a otra, trayendo y llevando el mensaje religioso de una localidad a otra, unas veces trabajando como jornalero agrícola (básicamente en los cultivos de la caña y café), otras veces como albañil, comerciante, empleado, trabajador informal, migrante. Es un indígena que maneja carismas, cuya autoridad es legitimada por el proceso y reconocimiento comunitarios con mayor diversidad de intereses locales. ${ }^{22}$

Con base en lo anteriormente expuesto, advierto que lo que puede ocurrir en este tipo de poblaciones con una gran diversidad religiosa es que poco a poco la población se desencante de lo religioso en la medida en que se polaricen cada una de las creencias religiosas existentes y se prosiga con la labor proselitista que parece no tener fin. Y aquí hay que tener presente que los católicos (objetivo de las estrategias de las campañas de evangelización, por parte de la mayoría de las agrupaciones religiosas existentes), cada vez son menos y los que quedan se han arraigado tan fuertemente a sus creencias que lo más probable es que veamos una competencia más agresiva para obtener conversos entre todos los moradores de la localidad. En donde la iglesia Católica no se quedará cruzada de brazos, viendo como los demás agrupaciones se desarrollan, sino que al igual que las demás tendrá que luchar por mantenerse y reproducirse, lo que significará acciones y estrategias no solo por parte de los miembros de la localidad sino por parte de las directrices de la iglesia a nivel diocesano, regional y nacional para la conservación, desarrollo e impulso de sus tradiciones, como la fiesta del Santo patrono, el fortalecimiento de sus costumbres como el día de muertos y otras más, las cuales deberán estar adaptadas y reconfiguradas a las

${ }^{22}$ No es de extrañar que las zonas indígenas sean los lugares más receptivos al proselitismo religioso y donde se presente la mayor diversidad religiosa. 
nuevas necesidades y situaciones que se viven en la localidad.

El conseguir conversos dentro de la localidad será más difícil y quizás la salida será buscarlos fuera de la cabecera, en las congregaciones y rancherías, incluso fuera del municipio, lo cual puede ser benéfico para la localidad ya que podría reforzar su importancia política y religiosa. También puede ocurrir que disminuya el número de agrupaciones religiosas debido a la competencia y depuración entre ellas mismas, donde el grande se coma al chico, o debido a lo abierto o cerrado en que se mantengan cada una de las congregaciones religiosas ante la competencia de los demás. Igualmente, puede ocurrir que, al incrementarse la competencia, se genere un ambiente de confusión religiosa entre los creyentes y les de lo mismo estar en una que en otra y ello de paso no a un alejamiento de lo religioso, sino a que pasen a engrosar la población de personas que se dicen "sin religión" pero que en realidad siguen siendo creyentes. Quizás este sea un buen caldo de cultivo para la entrada de nuevos movimientos religiosos. Es viable que se den algunas acciones autogestivas por parte de algunas congregaciones religiosas que las autoridades deberán analizar con detenimiento para no causar conflictos sociales o religiosos. La determinación con que las congregaciones tomen cada uno de estos procesos de coexistencia religiosa determinará el rumbo y el ethos que Mecayapan tome.

Hasta ahora el ethos de Mecayapan está marcado para los demás pueblos de la región como sui géneris, por los matices de un grupo étnico nahua y un pueblo no católico. Pero debido a la dinámica religiosa que observo en la región, estos mismos pueblos que miran a Mecayapan como una excepción, tendrán que admitir muy pronto que en sus localidades también se escuchan altavoces con diferentes discursos religiosos, aparentemente basados en la Biblia, pero con diferente aplicación y compromiso, observaran como se rompe con mucho más facilidad su "armonía", "inmutabilidad" y "unidad" de su comunidad tradicional indígena. $\mathrm{Y}$ es que la dinámica religiosa pese a la indiferencia o confusión que la diversidad religiosa provoca en algunos creyentes, ${ }^{23}$ cada vez será más sobresaliente, debido a que se fortalece y afianza con más opciones

23 Hay que resaltar que la dinámica religiosa no desmerece por la indiferencia que los moradores puedan tener ante tantas creencias, quizás se pierda el interés en lo doctrinal, litúrgico, quizás a muchos de ellos les parezca "que lo mismo da pertenecer a una que a otra", pero no se perderá el interés en la interacción social que estos grupos producen tanto a nivel social como con la divinidad. 
espirituales que se abocan a la salvación del individuo frente a la crisis moral y de representación de la sociedad civil, a cómo hacer frente a la persistencia de la miseria, la pobreza, el alcoholismo, la migración, la violencia familiar y social, que las autoridades con sus planes de recuperación y cambio no han logrado superar.

En fin, todas estas tendencias, nos hablan de un nuevo panorama religioso que hace más compleja la estructura social, diversificando las clases y los grupos sociales, incrementando nuevas culturas y subculturas. Sin embargo, estos procesos no suponen la sustitución de los otros. El campo religioso muta de campo religioso cerrado hegemonizado por el catolicismo, a campo religioso abierto con competencias interinstitucionales, nuevas adhesiones y nuevos reacomodos de los actores eclesiales y de los grupos de fieles. Habrá que estar al pendiente de cómo las viejas congregaciones religiosas, especialmente en el catolicismo, tienden a remarcar y restaurar el espacio perdido, así como observar cómo las diversas agrupaciones en competencia adquieren nuevas formas sincréticas y/o de religiones difusas.

Es en el marco de esta coexistencia y/o competencia religiosa, que la identidad étnica tendrá que redefinirse y donde lo religioso dibujará el ethos de estas localidades.

\section{Bibliografía}

ALVARADO LÓPEZ, Gilberto. El poder del espíritu, la visión política del pentecostalismo en el México contemporáneo. Tesis de Licenciatura en Etnohistoria. México: ENAH, 2004.

BAUTISTA, Tomás. Monografía de Huazuntlán y Mecayapan. Mecayapan: Inédito, 2000, pp. 1-32.

DE LA ROSA Muñoz Milca. El papel de las mujeres en la difusión de tres grupos pentecostales en Banderilla. IN: VÁZQUEZ PALACIOS, Felipe R. (coord). Las interacciones sociales y el proselitismo religioso en una ciudad periférica. México: CIESAS, Serie Antropológicas, 1999, pp.115-144.

DELGADO, Alfredo. La Candelaria, una fiesta que enaltece. México: Unidad Regional de Acayucan de Culturas Populares, $1^{\circ}$ de enero de 1992.

FORTES, Meyer y EVANS-PRITCHARD, Edward. Sistemas políticos africanos. IN: LLOBERA José R., (comp.). Antropología Política. Barcelona: Editorial Anagrama, 1979, pp. 85-105.

FROHELE, T. Bryan. Religious competition, comunity building and democracy in Latin America: Grassroot religious organizations in Venezuela. Sociology of religion, $\mathrm{n}^{0}$ 55: 2, 1994, pp. 145-162. 
GIMÉNEZ, Gilberto. Cambios de identidad y cambios de profesión religiosa. IN: BONFIL BATALLA, Guillermo (coord.). Nuevas identidades culturales en México. México: Consejo Nacional para la Cultura y las Artes, 1993.

GOBIERNO DEL ESTADO DE VERACRUZ. Enciclopedia municipal veracruzana. Veracruz: Secretaría Técnica, 1998.

INEGI. XII Censo General de Población y Vivienda Perfil sociodemográfico. 2000.

INEGI. XII Censo General de Población y Vivienda Perfil sociodemográfico. 2001.

INEGI. Anuario Estadístico de Veracruz. Tomo I y II. Xalapa: Gobierno del Estado de Veracruz, 2004.

INEGI. Información estadística, educación. 2004. Disponible en <http:// www.inegi.gob.mx/est/ default.asp?c=119., acceso en 3/11/2004.

JACKSON, Jean. Traducciones competitivas del evangelio en el Vapués, Colombia. América Indígena, México, $\mathrm{n}^{\circ}$ 44, 1984, pp. 44-94.

JUÁREZ CERDI, Elizabeth. Modelando a las evas: mujeres de virtud y rebeldía. Tesis de Doctorado en Antropología Social. Guadalajara: Universidad de Guadalajara, 2002.

Yajalón, ciudad confesionalmente pacífica. Ediciones Casa Chata, México, Vol. III, $\mathrm{n}^{0} 163,1989$.

LAW, Howard William. Mecayapan, Veracruz: an Ethnographic Sketch. Thesis Master of Arts. Austin: University of Texas, 1960,

MARROQUÍN ZAVALETA, Enrique. El conflicto religioso en Oaxaca (19761993). Tesis de doctorado. México: UAM-X, 1996.

MORALES PARRA, Martha. El impacto de la religión en la vejez. Tesis de licenciatura en Antropología Xalapa: Universidad Veracruzana, 2005.

RIVERA Farfán, Carolina. Dinámicas del crecimiento evangélico en Chiapas. El caso del valle de Pujiltic. Tesis de doctorado México: UNAM, 2003.

SAHLINS, Marshall. Hombre pobre, hombre rico, gran hombre, jefe: tipos políticos de Melanesia y Polinesia. IN: LLOBERA José R. (comp). Antropología Política. Barcelona: Editorial Anagrama. 1979, pp. 252-267.

URIBE CRUZ, Manuel. Identidad étnica y mayordomías en zonas de alta concentración industrial. El caso de los nahuas, popolucas y zapotecas del Istmo veracruzano en el siglo $X X$. Tesis de doctorado en Historia y Estudios regionales. Xalapa: Universidad Veracruzana, 2002.

VALLADO FAJARDO, Iván. Cambios en la religiosidad popular en Sudzal Yucatán. Ediciones Casa Chata, Vol. V, México, nº. 164, 1989.

VÁZQUEZ PALACIOS, Felipe R. El Protestantismo en Xalapa. Colección V centenario. Xalapa: Gobierno del Estado de Veracruz, 1991.

. La práctica de la fe y la ciudadanía en los evangélicos veracruzanos. En prensa.

VELÁZQUEZ HERNÁNDEZ, Emilia. Política ganadera recursos naturales en el 
trópico húmedo: El caso del municipio de Mecayapan. Relaciones, 1989, pp. 2363.

La fragmentación de un territorio comunal, tierra y tradición selectiva entre los popolucas y nahuas de la sierra de Santa Martha. Tesis de doctorado. México: Colegio de Michoacán, 2003.

WOLF, Eric. The aspects of the relations between groups in the complex societies in Mexico. IN: HEATH, Dwight B. (edit). Contemporary Cultures and Societies of Latin America. New York: Columbia University Press, 1970.

Colaboração recebida em 29/09/2009 e aprovada em 23/10/2009. 